\title{
VERKLARING VAN DE IN DE DOCUMENTEN VOORKOMENDE VREEMDE WOORDEN EN UITDRUKKINGEN. ${ }^{1}$ )
}

A.

alia, mannetjes-olifant zonder slagtanden: 310 .

amerie, extra rechten, boven de gewone tollen, te betalen te

Basra. In den tekst vertaald door maekelaerdye: 104.

amir, doubletvorm van emir, vorstentitel, bij de Compagnie vertaald door grootvorst: 67 . ammerouw, verbastering van omrah, titel voor hooge Mohammedaansche ambtenaren: 171, 205. anrongoeroe, Boegineesche titel, vertaald door opperhoofd: 265, 266.

areek, areka- of pinangnoot: 354, 355.

armanee of armene, naam voor de regeering van Madura in VoorIndië. Zie Corpus III, noot 4 op blz. 32: 350.

aroe, Boegineesche titel, meest vertaald door sultan: 23, 24, 263, $314,315$.

arsdast, verzoekschrift: 581, 582 . as a foetida, duivelsdrek, een harsachtige stof, als geneesmiddel gebruikt: $\mathbf{8 1}$. atimad-dauleth, Perzische titel voor den grootvizier of rijksbestuurder: 49, 135.

ayen of aya, achter persoonsnamen geplaatst ter aanduiding dat de genoemde een Brahmaan is: $317,318$.

\section{B.}

baar of bahar, gewichtseenheid van

3 pikoel of circa 375 pond. Zie Corpus III, blz. 607: 428, 431. bahadur, suffix bij vorstennamen, beteekenend held: 533 .

balai, vergaderplaats of „raadhuis": 431.

ballagat, klein inheemsch vaartuig in Voor-Indië: 204.

bandarye, zie sjahbandarye.

bappa, vader, titel voor bejaarden:

265, 266, 267.

bariga, Portugeesch, = buik, aanduiding voor tweede kwaliteit.

De woorden cabessa $=$ hoofd en $p e e=$ voet, duidden respect. eerste en derde kwaliteit aan: 241.

barra, andere naam voor baar of bahar. bassa, pasjah of pacha: 104.

1) De cijfers verwijzen naar de bladzijden, waar het woord voorkomt; de vetgedrukte cijfers naar die bladzijden, waar men een korte omschrijving en soms ook een literatuurverwijzing aantreft.

Van woorden, die herhaaldelijk voorkomen, zijn slechts enkele plaatsen opgegeven. 
batoer, Javaansch, volgeling of huisbediende, bij de Compagnie steeds gebruikt voor koelie of Heerendienstplichtige: 183, 368, $407,414,418,512,541,543$, 544.

battoor, zie batoer.

baxi, Mohammedaansche titel, hier gebruikt voor een militairen bevelhebber. Bakhshi is overigens betaalmeester: 457 . bedarka, convooigelden: 221 .

begler-begi, Perzisch, heer der heeren, titel voor een gouverneur: 97, 122.

benjo, zie bonjoy.

benjuin, bensuim $=$ benzoë, welriekende hars: 100 .

blandong, het verplichte kappen en wegsleepen van djatihout in de bosschen van Java's Noordoostkust: $\mathbf{5 4 2}$.

bobato, Moluksche titel voor regent. Vergelijk het Javaansche boepatih: 19, 28, 31, 63, 133, $139,154,156,174,176,216$, 220 , etc.

bok, boot gebruikt bij het lossen van op een reede liggende schepen. De roeiers heetten bokluiden: 588. .

bonjoy, titel van de Japansche ambtenaren, belast met het toezicht op de vreemde kooplieden: 282, 587.

bramine, $1^{\circ}$ priester: 297, 311, $350.2^{\circ}$ tolk of inheemsch schrijver: $87,88,109,204,205,207$, $209,210,317,318$.

\section{c.}

cabessa, zie onder bariga.

caffila, Arabisch kafilah, karavaan: 257.

candil, last van 480 pond: 240 , $288,347,348,350,351$. canoengooy, lees canongo, ambtenaar bij de landrente: 492 . capitan-laoet, titel in den Oostelijken Archipel, met de beteekenis van admiraal, maar ook veel gebruikt voor regenten: 96,103 , $128,134,139,155,250,265$, $330,340,341$, etc.

cardamon, welriekende specerij, - Maleisch kardamoenggoe: 240. caret, zie karet.

carga, baal zijde van 216 K.G. Zie

Corpus IV in de lijst der vreem-

de woorden: $72,73,74$.

cárgeeren, in prijs verhoogen: 116 . carra, Boegineesche titel: 265, 266, 267.

carroda, zie karoda.

casie, zie kadi.

casset, Hind. kasid, looper of koerier: 134.

catief, lijfeigene, banneling: 29.

cattie, gewichtseenheid van $1 / 100$ pikoel of 6 ons: 428 . caul, gunstbrief. Zie Hobson-Jobson in voce cowl: $86,171,203$, 205, 207, 310, etc.

cauris, schelpjes, gebruikt als betaalmiddel. Zie Pieter van Dam's Beschryvinge, II, I, glossarium in voce: $\mathbf{4 3 2}$.

caveeren, borg staan: 198 .

cayer, zie coir.

caymaal, vorstentitel aan de kust van Malabaar, vrijheer. Zijn vrouw wordt caymalinne genoemd: 159.

chaukidaar, zie chokidar. chiap, zie tjap.

chitty, suffix bij eigennamen, aanduidende dat de genoemde lid van de handelskaste was. Zie Hobson-Jobson in voce chetty: 354, 355.

chokidar, opzichter, waker: $\mathbf{3 5}$.

cobido, inheemsche ellemaat van circa 70 c.M. Zie Pieter van 
Dam's Beschryvinge, II, II, glossarium: 505 .

coir, de vezels van den klapperboom en het daaruit vervaardigde touw. Zie Hobson-Jobson in voce: 505.

colox, zie koelak.

cora-cora, gewapende prauw, ge-

bruikt voor de hongi-tochten:

$27,131,132,213,254,475$, etc. cortsje-bassie, zie kurtji-bashi. costumados, Portugeesch, gebruikelijke in- en uitvoerrechten: $311,501$.

curcuma, gele verfstof, bereid uit een crocusachtige plant, $\mathrm{Ma}-$ leisch koenjit. Zie Pieter van Dam's Beschryvinge, II, I, glossarium op crocus: 100. crain, zie karaeng.

D.

dabboe of daboe, kleine koperen munt: 107, 108, 589, 590, 591. daeng, Boegineesche adellijke titel: 23, 150, 151, 263, 265, 267, 275 , etc.

dain, zie daeng.

dallaal, Arabisch dalāl, makelaar: 582, 583.

daroga, hooge titel, hoofd of superintendent, gouverneur, hoofd van de munt: 221, 509, 538. dato of datoe, Boegineesche vorstelijke titel: 62, 265, 403.

defterdaer, zie dufterdar. dendi sjaboutra, zie sjaboutria. derogeeren, opheffen: 7 . dessave, titel van een districtshoofd op Ceilon: 355 .

destek, Perzisch dastak, keizerlijk paspoort of ,geleydebrief”. Zie VoGel, Ketelaar's Hofreis, noot 2 op blz. 55: 22, 140, 221, 492; 493, 538, 592.

dinar, kleine Perzische munt: 39, 312 . diwan-begie, Perzische titel, heer der justitie: 81.

djogoegoe, Ternataansche titel voor den rijksbesturder: 28,103 , $128,139,155,250,255,330$, 340,388 , etc.

djoöe, hooge Ternataansche titel, waarmee o.a. de sultan werd aangesproken, en beteekenende Heer: 31, 96, 439.

doelang, groote houten schotel, gebruikt bij het uitwasschen van ertsen in de kali: 477.

doesoen, tuin, boomgaard, sagobosch: 280, 438 .

drop, opium of amfioen: 581, 583. duan, ook geschreven diwan, titel $=$ hoofd der financiën, raad des konings: 104, 140, 234, etc. dufterdar, hoofd der belastingen: 104, 105.

\section{F.}

fanum, munt ter waarde van $1 / 12$ pagode. Er waren ook dubbele of koningsfanums (fanum-ragia) : 158, 348, 355, 501.

fausdar, titel met wisselende beteekenis, oorspr. voor een legerhoofd, later ook voor een gouverneur, het hoofd van de munt, etc.: $21,107,109,136,140,391$, 392, 432, 434, 492, etc.

firman, koninklijk bevelschrift, gunstbrief. Zie Vogel, o. 1. blz. 12: $140,171,205,234,257$, etc.

\section{G.}

galarrang of glarang, Makassaarsche en Boegineesche titel voor een districtshoofd: 263, 265, $266,277,305$, etc.

ganting of gantang, rijstmaat, bevattende circa $81 / 2 \quad \mathrm{~L}$. of $12 \frac{1}{2}$ pond: $186,357$.

gastos, Portugeesch $=$ onkosten: 40, 48, 158. 
geharpt, gezeefd met een z.g. harp: 185, 240, 371.

gelalo, gilalo, gilala, snel roeivaartuig: $132,254,475,525,572$, 600.

glarang, zie galarrang. goeserbanaar, Perzisch gurz-bar$d \bar{a} r$, letterlijk knotsdrager, hooge Perzische titel. Zie Vogel, o.l. blz. 50: 35 .

gomasto, Hindostani gomāshta, vertegenwoordiger, makelaar: 140, 163, 198, 221, 553, 537$539,563$.

guzarban, zie goeserbanaar.

H.

hamat, Javaansch amĕt, zooveel als een man dragen kan: 541 . hari-Moeloed, de dag van Mohammed's geboorte: 364 .

hasbulhockum, keizerlijk bevelschrift. Zie Hobson-Jobson in voce hosbolhookum: 68, 458. hatib, hatibi, zie katib.

hoedendragers, gebruikelijke aanduiding voor Europeanen in het rijk van den Grootmogol: 22, $390-392,538,563,582$.

hoekoem, ambtstitel op Noord-Celebes en omgeving, vroeger voor rechter, thans = afdeelingshoofd: $29,103,139,155,156$, 250 , etc.

\section{I.}

$i k j e$, Japansche lengtemaat van circa 3 Hollandsche ellen: 585, 586.

ikkeri, kleine gouden munt aan de

Malabaarsche kust, genoemd naar de plaats Ikkerie: 200. ingabey, zie ngabehi.

\section{J.}

jagăra, Javaansch, palmwijnsuiker: 513. jagerssuyker, zie jagăra.

jagir of jagier, erfelijk leenbezit, apanage. De houder van zoo'n bezit was de jagirdar: 21, 392. jamindar, zie jemadar. jaxa, rechterlijk ambtenaar, djak$s a: 416,419,514,540$.

jemadar, titel voor hoofd der politie, ook landvoogd: 140, 163, 205, 391, 434, 592.

jentief, of gentief, aanduiding voor de Hindoes in Voor-Indië, ter onderscheiding van de $\mathrm{Moo}$ ren of Mohammedanen. Het is het Portugeesche gentio, heiden: 207.

jerieb, Perzische lengtemaat van 4000 ges of el: 82.

jonkan, jonkom, joncquam etc., inen uitvoerrechten, van Tamil chungam. De inners dier rechten werden jonkeniers genoemd: 107, 135, 208, 297, 592.

\section{K.}

kadi, de bekende Moh. titel voor rechter, priester en ambtenaar, uitgesproken als kaadsjie, en op allerlei wijzen verbasterd, als casie, khagie, kasi, etc.: 104, 105, 123, 537, 564.

kamhout, gezochte soort roodhout: 182.

karaeng, Makassaarsche en Boegineesche titel voor prinsen en rijksgrooten: 196, 262-267, 277,306 , etc.

karet, schildpadshoorn: 59, 102, $133,228,247,252,285$, etc.

karoda, inspecteur, superintendent: 107, 108.

kasset, zie casset.

katib, chaîib, hatib, Maleisch, schrijver: 139, 309, 547. katsjil, zie ketjil.

katti, zie cattie.

ketgoda passent, zijde van prima 
qualiteit. Zie Corpus $I V$, blz. 605: 72, 73.

ketjil, prinselijke titel in de Molukken: $96,156,226,227,324$, $326,340,341$, etc.

kimelaha of quimalaha, Moluksche titel, tegenwoordig voor een kamponghoofd, in den Compagniestijd voor een stadhouder van den sultan van Ternate: $29,139,156,211-219$, 306, 308, 309, etc.

kitchil, zie ketjil.

koelak, kolok, rijstmaat, bevattende circa $5 \frac{1}{2}$ pond.

koenjit, zie curcuma.

koenting of konteng, hetzelfde als een prauw-majang, een snelle zeilprauw: $\mathbf{5 3 0}$.

koewala, Maleisch, riviermond: 90, 393, 479.

kojang, last van circa 30 pikoel: $368-370,379,380,384,404$ 407, 415, etc.

krissenwater, bij bezweringen gebruikt water, waarin de krissen gedoopt zijn. Zie Corpus III, noot 1 op blz. 30: 15, 125, 305. kroman, kleine Madoereesche prauw met uitleggers: 544 .

kurtji-bashi, hoofd van de Kurtji's of grenstroepen in Perzië: 76, 85.

kwala, zie koewala.

kwarto-diensten, kwartsvolk, Heerendienstplichten en -plichtigen in Ambon. Zie de Encyclopaedie van Ned. Indië: 332.

\section{L.}

$l a k$, Hind. lakh, een hoeveelheid van 100.000 , meest gezegd van ropyen: 221,510 .

latty, inheemsche naam van de Nederl. loge in Suratte: 459.

laxamanna, Maleische titel voor admiraal, echter ook gebruikt voor regent: 431 .

lomo, Boegineesche titel voor een districtshoofd: 263, 265.

lorrendraaiers, smokkelaars of blokkadebrekers: 230 .

M.

majang, zie koenting: 541, 543.

man, gewichtseenheid in Perzië en Indië. De z.g. man-tebries was circa 3 K.G.: 71, 72, 492.

manuaar, pachter der belastingen aan de Koromandelsche kust:

172, 205, 206.

maon, zie man.

marambin, rijksgroote aan de kust van Malabaar: 288.

marinjo, Moluksche titel voor een ondergeschikt ambtenaar, oppasser: 488, 576.

mardyker, vrije Christen inlander: 231, 233, 299.

massoel, te betalen rechten in Suratte, 257.

matcaal of matical, Perzisch mus$k a l$, een gewicht, onderdeel van de man. Zie Corpus IV, noot 5 op blz. 210: 71, 72 .

marsaoli, Gorontalosche titel voor een districtshoofd: 29, 103.

meyhaar el momaleek, Perzische titel voor den oppermuntmeester: 81 .

mier-beker, heeft in den tekst de beteekenis tolplaats. Het Perzische mirbahr beteekent echter havenmeester. De Versameling der Woorden geeft: mierbaar, waterschout of strandvoogd. WILSON zegt: mir-bahr, customor harbour-master; mir-bahri, port-duties, also taxes on boatand ship-building: $\mathbf{4 3 6}$.

modseddie, hooge ambtenaar der kanselarij in het rijk van den 
Grootmogol: 35, 140, 205, 391, 434, 435, 439, 445, 492.

moetsilka, schriftelijk vastgelegde verplichting, verbandschrift. Zie Corpus IV, noot 3 op blz. 222: $141,390,392$.

molla, Mohammedaansch geleerde, kenner van den koran:: 45, 123. mooren, de algemeene aanduiding voor Mohammedanen: 41, 134, $200,245,429$.

mostaffesaes, soldaten of wakers in Perzië: 42.

mustoffie, hooge Perzische ambtenaarstitel, in den tekst omschreven door ,principale secretarissen van 's conings gehijmcabinet". In het algemeen duidt het woord financieele ambtenaren aan en wordt dan ook wel vertaald door belastinggaarder of tollenaar. Het maakt deel uit van de titels mustoffie e momalek, hoofd van de munt en mustoffie $e$ chazineh of mustoffiecassa, kanselier van de schatkist: $76,77,86,312,313$.

\section{N.}

nabab, algemeene titel in VoorIndië voor een gouverneur of onderkoning: $21,35,136,141$, $203,205,221,256$, etc.

nabies, zie nevis.

naib, doubletvorm van nabab, zie aldaar.

naik, vorstentitel aan de kust van Madura, „vrijheer of grave": 200.

naikar, zie naukar.

nairos, leden van de militaire

kaste op Malabaar, „ridders”: 240.

nasir, hooge ambtenaar aan het

Perzische hof: 48.

naukar, vertegenwoordiger van den naik. Zie noot 3 op blz. 31 van het derde deel van dit werk: 311.

$n a w a b=n a b a b$.

neli, Voorindische naam voor rijst

in den bolster, padi: 88,158 , $318,427$.

nesser of nesserane, geschenk aan een autoriteit in Bengalen: 391, 392, 537, 539.

nevis, schrijver : $501-503$.

ngabehi, titel voor Javanen van vorstelijken bloede: 146, 147, 405.

ngoffamanjirah, Moluksche titel, thans voor een kamponghoofd: in de $17 \mathrm{de}$ en $18 \mathrm{de}$ eeuw een districtshoofd: $139,156,308$, 309, 388, 389.

nisaan, vorstelijk gunstbewijs in Bengalen, „princelijk bevelschrift": 234.

nuzzer, zie nesser.

\section{o.}

oekoeng, zie hoekoem.

ola, gedroogd palmblad, o.a. als schrijfmateriaal gebruikt, waardoor het woord ook den zin kreeg van brief en zelfs van privilege: $159,355$.

orang-kaja, Maleische titel voor hoofd: $229-233,333,334,336$. 337.

ottena, autoriteit op het eiland Decima in Japan: 587.

\section{P.}

pagode, gouden munt ter waarde van 120 Hollandsche stuivers, zoo genoemd omdat er een pagode (tempel) op afgebeeld was: $172,200,202,206,348$, 355,501 . 
palenquin, palankijn of draagstoel: $87,318$.

pandidaar, titel van een regent aan de kust van Koromandel: 311, $501-503$.

pantsjaling, inheemsch zeilvaartuig in den Archipel: 468.

pardao, in Goa geslagen zilveren munt ter waarde van 300 reis: $310,503$.

parra, rijstmaat, bevattende circa 40 pond: $158,160$.

parwanna, privilegebrief, „onderkoninglijk bevelschrift" of "ordres der duwans": $19,20,35$, $87,107,108$, tc.

paseban, gehoorplaats op de aloon-aloon: 243.

patih, plaatsvervanger van den vorst of een regent: 407, 408, $416,419,514$, etc.

pee, aanduiding voor derde kwaliteit, zie onder bariga hiervóór: 241.

pees, -stuks. Zie Pieter van Dam's Beschryvinge, I, II, glossarium: 92, 180, 200.

peesjewee, ambtenaar aan de kust van Koromandel, ,,seegulbewaerder": 501-503.

peeskes, in Bengalen te betalen premies voor het recht van handeldrijven, verplichte schenkingen, ,,recognitiepenningen": 221. pecceeren of pexeeren, misdrijven.

Vgl. Latijn peccare $=$ zondigen: 362, 376, 399.

pepatty, zie patih.

perganna, Hind. pergana, district: 21, 140, 198, 221, 222, 234.

peshwa, hoofd der Mahratta's: 311.

pesuway, zie peshwa.

phaar, inheemsch vaartuig aan de Koromandelkust: 355 .

poenggawa, Boegineesche titel voor een hoofd van lageren rang: 276 . pongoulou, pongloe, pongul, titel voor een regent aan Sumatra's Westkust, verbastering van panghoeloe: 98, 100, 261, 323.

Q.

quartsvolk, zie kwartsvolk. quimelaha, zie kimelaha.

\section{R.}

racam, koninklijk bevelschrift. Zie WILSON in voce rakam. Het woord is door de Portugeezen verbasterd tot regam: 71,73 , $77,79,80,134$, etc. rackadaring, geldafpersing: $\mathbf{1 7 1}$. radery, zie rahdar en rahdari. radix-China, gedroogde wortel, als medicijn bij huidziekten gebruikt: 72 .

radja-moeda, kroonprins: 305 . ragia, zie fanum.

ragiador, titel voor een regent aan de kust van Malabaar: 159, 240, $286,352$.

rahdar, inner van wegtollen (rah $=$ weg). De tolgelden werden rahdari genoemd: 74, 84, 259. rakam, zie racam. ranrang, titel op Zuid-Celebes: 314.

rauw, hooge titel aan den kust van Koromandel, Hindostani rao: 501-503.

regam, zie racam.

rompe, rimpel, plooi, vermoedelijk ook de gracht of greppel om een versterking: 530 .

\section{S.}

sabandhaar, zie sjahbandar.

sadaha, Ternataansche titel, thans voor den opzichter van het sultanserf: 134.

sahib, aanspreektitel voor hooger 
geplaatsten in Voor-Indië, thans algemeen gebruikt tegenover Europeanen: 317, 354, 355. sahid, zie said.

said, Moh. titel, oorspronkelijk alleen toekomende aan de afstammelingen van Mohammed's dochter Fatimah: 268, 537.

sair, verzamelnaam voor alle te betalen doorvoerrechten enz. in Bengalen: 140.

salahoekoem, titel van de stadhouders des konings van Ternate op de omliggende eilanden: $356,358$.

samoekar, ambtenaarstitel op Koromandel: 35 .

sapandiaar, ambtenaar bij de inen uitvoerrechten: 35 .

saraaf, geldwisselaar, kassier: 268.

sardar, ook wel sirdar, commandeur: 313.

sassefras, boom, die zoowel roodhout levert als de welriekende massooi of koelit-lawang: 336, 438.

sedjek, zekere belasting van 1 procent in Perzië: 74.

seet, zie zeet.

sengadji, in de Molukken gebruikelijke titel voor een regent of districtshoofd: $29,32,103,134$, $155,156,211-219$, etc.

sennet, privilege of charter in Suratte: 142.

serkaer, zie sircar.

shekdar, ontvanger der belastingen: 197, 198.

simedaar, zie jemadar.

sircar, landstreek, gebied: 163, 198.

sjaboutria, de koninklijke waag te Hoegli: 140.

sjahbandar, havenmeester, wiens gebied sjahbandarye genoemd werd: $77,139,167,168,306$, $366,399,407,414,418$, etc. sjonkan, zie jonkan. sjoukidaar, zie chokidar. soeloewatang, districtshoofd op Zuid-Celebes: 265, 266.

souba, provincie: $35,140,221,301$, etc.

soubadar, gouverneur eener provincie; $35,87,88,163,581$. soubaschap, het gebied van een soubadar: 391, 434, 435, 439, 510.

staak, tak van een familie of geslacht: 535,536 .

\section{T.}

tabijn, Perzische titel, volgeling, plaatsvervanger: 73 .

takar, maat, ook drinkvat: 415, $419,421,513,515$.

takiet, Hind. takid, bevelschrift: 87, 108, 135, 317, 318.

takker, zie takar.

tallica, factuur of inventarislijst. Zie Hobson-Jobson in voce: 97, 434, 435.

tanksaal, muntgebouw. Zie Hobson-Jobson in voce tuxall: 107, 108.

tannidaar, zie thanadar.

thail, een gewicht van $371 \frac{1}{2}$ gram. Ook een geldswaarde van zooveel goud of zilver: 584, 585 .

thanadar of tannadar, officier van het leger of van de politie: 205, 592.

thengka, Hind. tanka, geld: 142. tjap, sjap of chiap, merk of stempel; het merken of stempelen heet tjappen: $258,320,459,468$, $580,590$.

tjapar, een bode te paard in Perzië: 48.

tjatja, gezin; tjatjasgelden, hoofdgelden op Java: 535, 543 .

toekoe, kleine balk, paal, waarschijnlijk is dit het Maleische toegoe: 180. 
toemailalang, rijksbestuurder in Zuid-Celebes: $\mathbf{3 0 6}$.

toemenggoeng, hooge Javaansche titel, bij de Compagnie gebruikt voor verschillende inheemsche ambtenaren, als ontvanger, fiskaal, baljuw, etc.: $490,508,512$, 536, 539, 542, 543.

toman of thoman, Perzische rekenmunt ter waarde van circa 42,50 gld.: $39,41,43,71-78,97,121$, 122 , etc.

tomilalang, zie toemailalang. tommongon, zie toemenggoeng. trocqueeren, Fransch troquer, ruilen, verhandelen: 232 .

\section{U.}

uitslag, toegift of overwicht: 486 .

\section{V.}

vigiador, Portugeesch, bewaker, titel van een politie-officier: 205. vlintsteenen, vuursteenen. Vgl. het Duitsche Flint: 348.

\section{W.}

wackinawees, wackanawies, in den tekst vertaald door dagregisterhouder. Zie voor dit woord VoGEL, Journaal van Ketelaar, blz. 31 met noot 1: 67, 68 .

wakil, Arabisch, plaatsvervanger, vertegenwoordiger: 390,391 , $392,433,439,445$, etc.

wankang, kleine Chineesche jonk: 166, 167, 450.

wazir, minister, grootvizier; wazir ul momaleek, opperste wazir: 67 . wetangers, aanduiding voor de echte Javanen, tegenover de Bantammers. $($ Wetan $=$ Oost; ze worden ook Ooster-Javanen genoemd): 555 .

\section{Z.}

zeet, zetel. Ter zeet begeven = zich neerzetten: 172, 208. 